\title{
TGF- $\beta 1$ Expression in Contractured Achilles Tendon among Diabetic Foot Patients: a Semi-Quantitative Study
}

\author{
R. A. Primadhi', H. Gunawan², S. Rachmayati ${ }^{3}$, H. N. Rasyid ${ }^{1}$ \\ ${ }^{1}$ Department of Orthopaedics and Traumatology, Universitas Padjadjaran Medical School, \\ Bandung, Indonesia \\ 2 Department of Dermato-Venereology, Universitas Padjadjaran Medical School, Bandung, Indonesia \\ ${ }^{3}$ Department of Clinical Pathology, Universitas Padjadjaran Medical School, Bandung, Indonesia
}

\section{CORRESPONDING AUTHOR:}

Raden Andri Primadhi

Department of Orthopaedics

and Traumatology

Universitas Padjadjaran Medical School

Jalan Pasteur 38

Bandung, Indonesia 40161

E-mail: randri@unpad.ac.id

DOI:

10.32098/mltj.02.2021.09

LEVEL OF EVIDENCE: $3 B$

\begin{abstract}
SUMMARY
Background. Increased plantar pressure when walking is among the pathogenesis of diabetic foot ulceration. Contractured Achilles tendon will biomechanically results in increased plantar pressure. In this study, we summarize the correlation between increased transforming growth factor $\beta 1$ (TGF- $\beta 1$ ) expression and the development of Achilles tendon contracture in diabetic foot patients.

Methods. Thirty diabetic foot patients with indication for surgery were enrolled to this study and divided to two groups. Case group consisted of patients presenting Achilles tendon contracture, in contrary with control group. During surgery, the specimens of Achilles tendon were taken and analysed semi-quantitatively by immunohistochemical (IHC) examination. Achilles contracture as a dependent variable was concluded from physical examination, and later by histological findings.

Results. IHC revealed that the positive TGF- $\beta 1$ expressions were found in all case and control group cases, respectively. There were different results between both groups regarding the expression strength, specifically $2 / 15$ vs $8 / 15$ for +3 result, $10 / 15$ vs $6 / 15$ for +2 result, and $3 / 15$ vs $1 / 15$ for +1 result. Linear regression analysis showed significant result $(\mathrm{p}<0.05)$ of age and TGF- $\beta 1$ expressions as the determinants of Achilles tendon contracture, while the results for sex, body mass index (BMI), and $\mathrm{HbA1c}$ were insignificant.

Conclusions. Chronic hyperglycemia was thought to be one of the etiology of Achilles tendon contracture through the cascade involving the advanced glycation end products (AGEs) accumulation. However, these results suggested that the HbA1c level is not a sole determinant, and TGF- $\beta 1$ should be considered as a contributing factor for Achilles tendon contracture during the development of diabetic foot ulcerations.
\end{abstract}

\section{KEY WORDS}

Achilles tendon; contracture; diabetes; immunobistochemistry; TGF- $\beta 1$.

\section{BACKGROUND}

Diabetes mellitus (DM) is a chronic metabolic condition characterized by persistent hyperglycemia with resultant morbidity and mortality related to its microvascular and macrovascular complication (1). Such a profound demographic shift is likely to yield a corresponding increase in the prevalence of diabetes chronic complications, including those in the lower extremity, the diabetic foot (2). Diabet- ic foot is a complication of DM leading to most feared non-traumatic lower limb amputation. As many as $15 \%$ of diabetic patients will suffer from ulcer in their lifetime, and $12-24 \%$ will undergo amputation (3). Since most diabetic patients who have an amputation have foot ulcers, if foot ulcers can be eliminated, most amputations in diabetics could potentially be prevented (4). 
Tendon imbalance, especially due to Achilles and gastrocnemius-soleus tightness, may cause an increased stress in the forefoot. Increased stress in the forefoot can cause a callus, followed by a forefoot ulcer (4). Prior comparison between diabetic and nondiabetic patients suggests that equinus may be more prevalent in diabetic patients. Coombes et al. had also concluded that Achilles tendon from individuals with type 2 diabetes were thicker compared to inactive individuals without diabetes (5). Nonetheless, these data are insufficient to prove causality and lack the required power to prove or disprove these relationship $(4,6)$.

Hyperglycemia in diabetic patients is responsible for the presence of high levels of nonenzymatically produced advanced glycation end-products (AGEs) in patients with diabetes. AGEs play an important role in cell signaling by interacting with specific receptors that link to the activation of adhesion molecules, proinflammatory cytokines and growth factors, thus contributing to the pathogenesis of diabetic complications (7). AGEs are able to stimulate directly the production of extracellular matrix (ECM) (8). However, despite the recognized importance of AGEs in the development of age and diabetes related conditions, there are still several important open questions regarding their role in the onset and progression of connective tissue disease (9). Why contracture is not commonly found in all diabetic patients is not yet fully understood. Other than hyperglycemia, factors that regulate ECM formation include multiple forms of growth factor such as transforming growth factor-beta (TGF- $\beta$ ). The important role of growth factors in the pathogenesis of diabetic long-term complications was suggested by their increased concentrations in target tissues. An excess of growth factor is implicated in tissue where fibrosis predominates, whereas a lack of growth factors occurs in diabetic neuropathy and wound healing (7). Among the TGF- $\beta$ isoforms, TGF- $\beta 1$ has been known to promote wound healing and also fibrosis $(10,11)$. In our literature review, there is still insufficient study on pathogenesis of diabetic ulcer focusing on the development of equinus due to contracture of Achilles tendon. In this study, we evaluated immunohistochemical expression of TGF- $\beta 1$ in Achilles tendon tissue by comparing between contractured and non-contractured tendon.

\section{MATERIALS AND METHODS}

This was a case-control study of 30 subjects admitted to Hasan Sadikin Hospital, Bandung, Indonesia from January to September 2020. Target population is diabetic foot ulcer patients with indication for surgery such as debridement or deformity correction including Achilles tendon lengthening. Achilles tendon lengthening procedures were performed by Z-lengthening in open manner to facilitate the tendon specimen collection. Study group consists of diabetic foot ulcer patients with Achilles tendon contracture, and control group consists of diabetic foot ulcer patients without Achilles tendon contracture. We reckoned the Achilles tendon contracture if the ankle dorsiflexion was less than $10^{\circ}$ with the knee flexed as described in a definition of equinus (12). Subjects were taken in accordance to inclusion and exclusion criteria and selected by consecutive sampling. Demographic characteristics and other information were extracted from the electronic medical records. This study was conducted ethically according to international standards as described by Padulo et al. (2018) (13).

Inclusion criteria for study group included: 1) confirmed type 2 diabetes mellitus, 2) incur foot ulceration less than 4 weeks onset, 3) sustain indication for surgery, 4) present Achilles tendon contracture, and 5) age not less than 18 years old. Inclusion criteria for control group is the same for criteria number 1,2,3 and 5. The distinction between both groups is at number 4, which was without Achilles tendon contracture. Exclusion criteria for both groups consisted of 1) prior ankle deformity due to congenital disease or trauma, 2) prior Achilles contractures attributed to scarring, 3 ) any medical comorbidities causing drop foot e.g., spinal problem, 4) patient with contraindication for surgery, and 5) patient who refuse to participate in the study.

Demographic data and related clinical characteristics were collected, including bony mass index (BMI) and $\mathrm{HbA1c}$ levels. Independent variable in this study was TGF- $\beta 1$ in Achilles tendon, analysed semi-quantitatively using immunohistochemical studies by an experienced histopathologist. Dependent variable was the contracture of Achilles tendon, concluded from ankle range of motion measurement using a goniometer with $90^{\circ}$ knee joint flexion and expression of fibronectin, a glycoprotein which is normally present in ECM and plasma with thrombotic, inflammatory, angiogenic, and fibrogenic functions. Fibronectin was observed for its crucial role in cell adhesion, growth, migration, and differentiation (14-16).

\section{Sample Collection and analysis}

During the surgery, a $5 \mathrm{~mm} \times 5 \mathrm{~mm} \times 5 \mathrm{~mm}$ specimen of the Achilles tendon was obtained from each patient at the mid-substance (figure 1). Immunohistochemical analyses of TGF- $\beta 1$ and fibronectin were performed using the avidin-biotin complex method. The specimens were fixed in neutral buffered formaldehyde and processed into paraffin wax by standard histological methods prior to immunostaining. Three microns thick sections were cut and placed, then dried overnight. The sections were incubated 


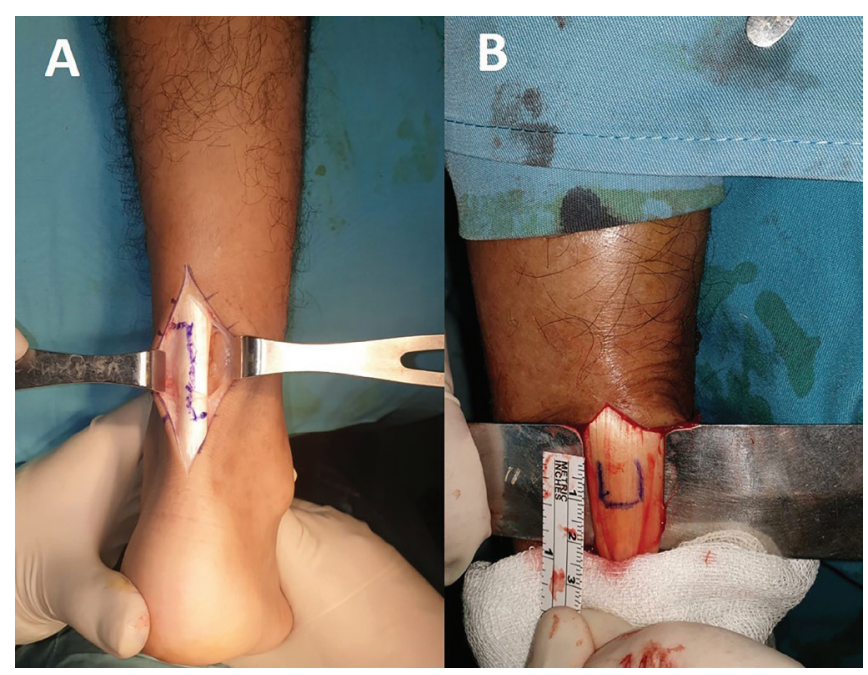

Figure 1. Tendon excision to obtain samples. (A) In case group with concomitant Z-lengthening procedure. (B) In control group.

with the primary antibodies against TGF- $\beta 1$ and fibronectin for 1 hour in a humidity chamber. Biotin-labelled secondary antibodies were utilized for 7 minutes at $45{ }^{\circ} \mathrm{C}$. The streptavidin-horseradish peroxidase detection system was then applied to the capillary channels. After drainage, the tissue sections were ready for the chromogen reaction with 3-amino-9ethyl carvazole. The sections were counterstained with hematoxylin subsequently. The specimens were reviewed by an expert histopathologist. The stained slides were scanned at low power view. Cytoplasmic staining of TGF- $\beta 1$ was scored by the percentage of positive cells ( 0 : $<10 \%, 1: 10-25 \%, 2: 26-50 \%$, and $3:>51 \%$ ) (17). Assessment of fibronectin staining included initial low power view and subsequent high-power observation. The observations were graded according to the following pattern: negative staining $(0)$, focal weak staining $(1+)$, intense patchy staining $(2+)$, and intense diffuse staining $(3+)$.

\section{Statistical analysis}

Demographic and clinical characteristics were summarized in frequencies and percentages for categorical variables and in appropriate measures of central tendency and dispersion for continuous variables. Linear regression analysis was used to examine the associations between selected variables and outcomes of interest (development of Achilles tendon contracture). A p-value was less than 0.05 was considered to be statistically significant. All statistical analyses were performed using IBM SPSS Statistics for Windows, version 25 (IBM Corp., Armonk, N.Y., USA).

\section{Ethics permission}

This study was conducted after the ethical clearance had been granted from the Research Ethics Committee of Universitas Padjadjaran (Institution Review Board No. 00008626), No.780/UN6.KEP/EC/2019. Ethical aspect was applied to all subjects, including respect for person, beneficence, non-maleficence, and justice. The copy of ethical approval would be available upon request.

\section{RESULTS}

\section{Clinical characteristics}

The 15 patients presenting Achilles tendon contracture in the case group included 8 men and 7 women aged from 51 to 72 years (mean age: $63.13 \pm 6.91$ years). The 15 patients in the control group had diabetic foot without Achilles tendon contracture, including 6 men and 9 women aged from 46 to 68 years (mean age: $57.2 \pm 6.07$ years). BMI mean in case and control group were $26.88 \pm 4.02 \mathrm{~kg} / \mathrm{m}^{2}$ and $24.54 \pm$ $4.87 \mathrm{~kg} / \mathrm{m}^{2}$, respectively. HbA1c level median were similar, specifically $7.8 \%$ (range 5-14) in case group and 7.8\% (range 5.6-13) in control group.

\section{Immunohistochemical findings}

Each slide was reviewed by an expert histopathologist and scored in areas with the highest score based on the scoring system disregarding the dimensions of the stained areas (table I):

1. TGF- $\beta$ isoforms: the TGF- $\beta$ expression score, as illustrated in figure 2, was significantly higher in the case group than in the control group $(\mathrm{p}=0.025)$. The median score was $2(+2)$ in the control group versus $1(+1)$ in the control group.

2. Fibronectin: with regard to fibronectin expression (figure 3), four types of expression patterns were interpreted. Most common appearance found in case group was intense diffuse staining (11/15), in contrary with $0 / 15$ in the control group.

\section{Determinant analysis}

The results from logistic regression analysis on the factors associated with Achilles tendon contracture and increased fibronectin expression are presented in table II. Among the tested variables, age and TGF- $\beta 1$ expression score were significantly associated with the contracture $(p=0.036$ and $\mathrm{p}=0.031$, respectively), while sex, BMI, and HbA1c level were not. 
Table I. Clinical and histological findings.

\begin{tabular}{|c|c|c|c|c|c|c|c|c|}
\hline No & Age & Sex & BMI & HbA1c & $\begin{array}{c}\text { TGF- } \beta \\
\text { expression }\end{array}$ & $\begin{array}{c}\text { Fibronectin } \\
\text { expression }\end{array}$ & Ankle RoM & Contracture \\
\hline 1 & 67 & $\mathrm{~F}$ & 29.9 & 11 & +2 & +3 & $\mathrm{PF} 25^{\circ}-\mathrm{DF} 0^{\circ}$ & + \\
\hline 2 & 64 & $\mathrm{~F}$ & 32.47 & 7.6 & +2 & +1 & $\mathrm{PF} 40^{\circ}-\mathrm{DF} 20^{\circ}$ & - \\
\hline 3 & 68 & $\mathrm{~F}$ & 28.44 & 9 & +2 & +1 & $\mathrm{PF} 30^{\circ}-\mathrm{DF} 10^{\circ}$ & - \\
\hline 4 & 58 & $\mathrm{M}$ & 29.33 & 14 & +3 & +3 & $\mathrm{PF} 40^{\circ}-\mathrm{DF} 0^{\circ}$ & + \\
\hline 5 & 52 & M & 25.77 & 7.4 & +2 & +3 & $\mathrm{PF} 10^{\circ}-\mathrm{DF} 5^{\circ}$ & + \\
\hline 6 & 47 & $\mathrm{M}$ & 26.77 & 5.6 & +1 & +1 & $\mathrm{PF} 50^{\circ}-\mathrm{DF} 10^{\circ}$ & - \\
\hline 7 & 62 & $\mathrm{~F}$ & 19.77 & 5.7 & +1 & +2 & $\mathrm{PF} 30^{\circ}-\mathrm{DF} 15^{\circ}$ & - \\
\hline 8 & 64 & $\mathrm{M}$ & 30.38 & 8.6 & +2 & +3 & $\mathrm{PF} 5^{\circ}-\mathrm{DF} 5^{\circ}$ & + \\
\hline 9 & 64 & $\mathrm{M}$ & 26.56 & 9 & +1 & +2 & $\mathrm{PF} 15^{\circ}-\mathrm{DF} 0^{\circ}$ & + \\
\hline 10 & 61 & M & 30.85 & 7 & +2 & +3 & $\mathrm{PF} 30^{\circ}-\mathrm{PF} 5^{\circ}$ & + \\
\hline 11 & 54 & $\mathrm{M}$ & 25.78 & 6.6 & +2 & +2 & $\mathrm{PF} 30^{\circ}-\mathrm{DF} 10^{\circ}$ & - \\
\hline 12 & 58 & $\mathrm{~F}$ & 19.97 & 12 & +2 & +1 & $\mathrm{PF} 25^{\circ}-\mathrm{DF} 15^{\circ}$ & - \\
\hline 13 & 53 & $\mathrm{~F}$ & 28.30 & 9 & +3 & +1 & $\mathrm{PF} 40^{\circ}-\mathrm{DF} 20^{\circ}$ & - \\
\hline 14 & 69 & $\mathrm{M}$ & 22.22 & 6.4 & +2 & +3 & $\mathrm{PF} 15^{\circ}-\mathrm{DF} 0^{\circ}$ & + \\
\hline 15 & 59 & $\mathrm{M}$ & 19.53 & 7.8 & +2 & +1 & $\mathrm{PF} 30^{\circ}-\mathrm{DF} 15^{\circ}$ & - \\
\hline 16 & 72 & M & 25.77 & 9.8 & +2 & +3 & $\mathrm{PF} 15^{\circ}-\mathrm{DF} 5^{\circ}$ & + \\
\hline 17 & 53 & $\mathrm{~F}$ & 32.03 & 5.7 & +1 & +1 & $\mathrm{PF} 30^{\circ}-\mathrm{DF} 20^{\circ}$ & - \\
\hline 18 & 70 & M & 19.53 & 5 & +2 & +3 & $\mathrm{PF} 20^{\circ}-\mathrm{DF} 0^{\circ}$ & + \\
\hline 19 & 58 & $\mathrm{~F}$ & 24 & 8 & +2 & +2 & $\mathrm{PF} 30^{\circ}-\mathrm{DF} 15^{\circ}$ & - \\
\hline 20 & 46 & $\mathrm{~F}$ & 19.83 & 6.80 & +1 & +2 & $\mathrm{PF} 20^{\circ}-\mathrm{DF} 20^{\circ}$ & - \\
\hline 21 & 64 & $\mathrm{M}$ & 28.3 & 7.2 & +1 & +1 & $\mathrm{PF} 30^{\circ}-\mathrm{DF} 15^{\circ}$ & - \\
\hline 22 & 68 & $\mathrm{~F}$ & 30.46 & 11.6 & +1 & +2 & $\mathrm{PF} 30^{\circ}-\mathrm{DF} 5^{\circ}$ & + \\
\hline 23 & 57 & $\mathrm{~F}$ & 17.78 & 10.4 & +1 & +1 & $\mathrm{PF} 15^{\circ}-\mathrm{DF} 15^{\circ}$ & - \\
\hline 24 & 52 & $\mathrm{~F}$ & 26.21 & 12 & +2 & +3 & $\mathrm{PF} 40^{\circ}-\mathrm{DF} 5^{\circ}$ & + \\
\hline 25 & 51 & $\mathrm{~F}$ & 30.38 & 7 & +2 & +3 & $\mathrm{PF} 15^{\circ}-\mathrm{DF} 0^{\circ}$ & + \\
\hline 26 & 59 & $\mathrm{M}$ & 25.71 & 8 & +1 & +1 & $\mathrm{PF} 40^{\circ}-\mathrm{DF} 15^{\circ}$ & - \\
\hline 27 & 69 & $\mathrm{M}$ & 25.65 & 7.2 & +2 & +3 & $\mathrm{PF} 30^{\circ}-\mathrm{PF} 5^{\circ}$ & + \\
\hline 28 & 64 & $\mathrm{~F}$ & 19.10 & 7.8 & +3 & +2 & $\mathrm{PF} 15^{\circ}-\mathrm{DF} 5^{\circ}$ & + \\
\hline 29 & 66 & $\mathrm{~F}$ & 31.11 & 6 & +1 & +2 & $\mathrm{PF} 10^{\circ}-\mathrm{DF} 0^{\circ}$ & + \\
\hline 30 & 56 & M & 19.53 & 13 & +1 & +2 & $\mathrm{PF} 30^{\circ}-\mathrm{DF} 15^{\circ}$ & - \\
\hline
\end{tabular}

BMI: Body mass index; HbA1c: Glycated haemoglobin level; TGF- $\beta$ : Transforming growth factor- $\beta$; RoM: Range of motion; DF: dorsiflexion; PF: plantarflexion.

\section{DISCUSSION}

The main characteristics of diabetes mellitus is hyperglycemia. Persistent overnutrition creates a steady level of high blood glucose that is toxic to macrovascular and microvascular systems. Skin and soft-tissue infections are of particular concern in patients with diabetes mellitus, especially those with comorbid peripheral vascular disease $(18,19)$.
One possible cause of wound healing defects in diabetes patients has been associated with altered biology of bone marrow-derived endothelial progenitor cells. Pathological analysis has revealed abnormal microvessels that can be cuffed with collagen, laminin, fibronectin, or fibrin (20). Altered immune function is one potential effect in diabetic patients. Changes in leucocyte function figure prominently 


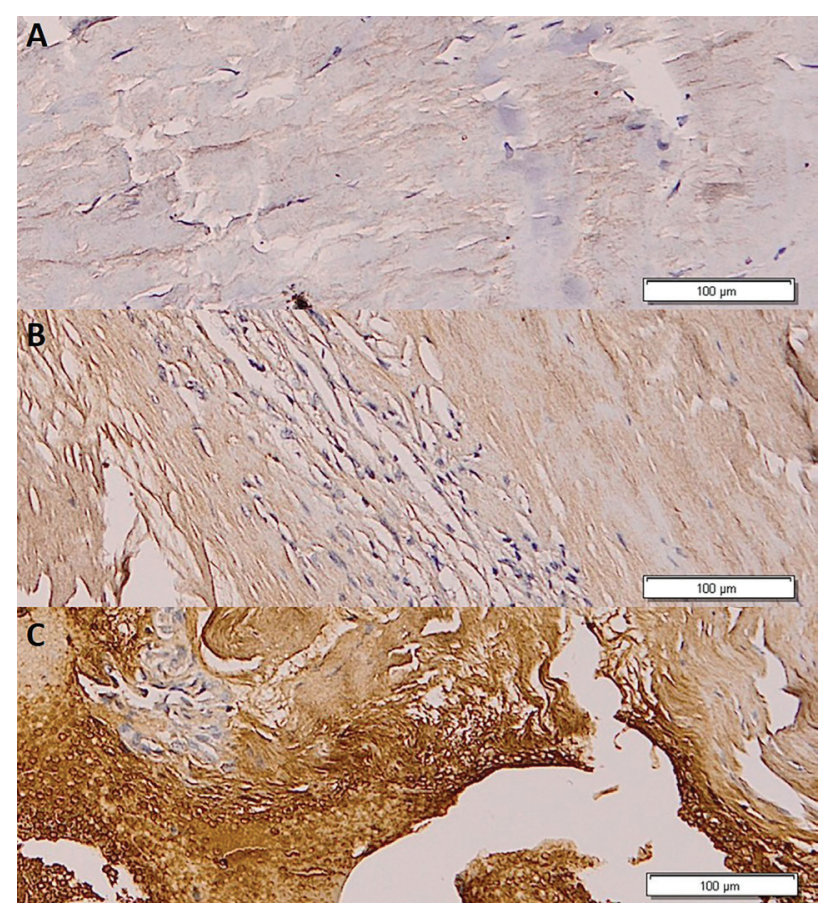

Figure 2. Immunohistochemical expression of TGF- $\beta 1$ in Achilles tendon according to cytoplasmic staining score in fibroblast and inflammatory cells. (A) +1 ; (B) +2 ; (C) +3 ; magnification 100x.

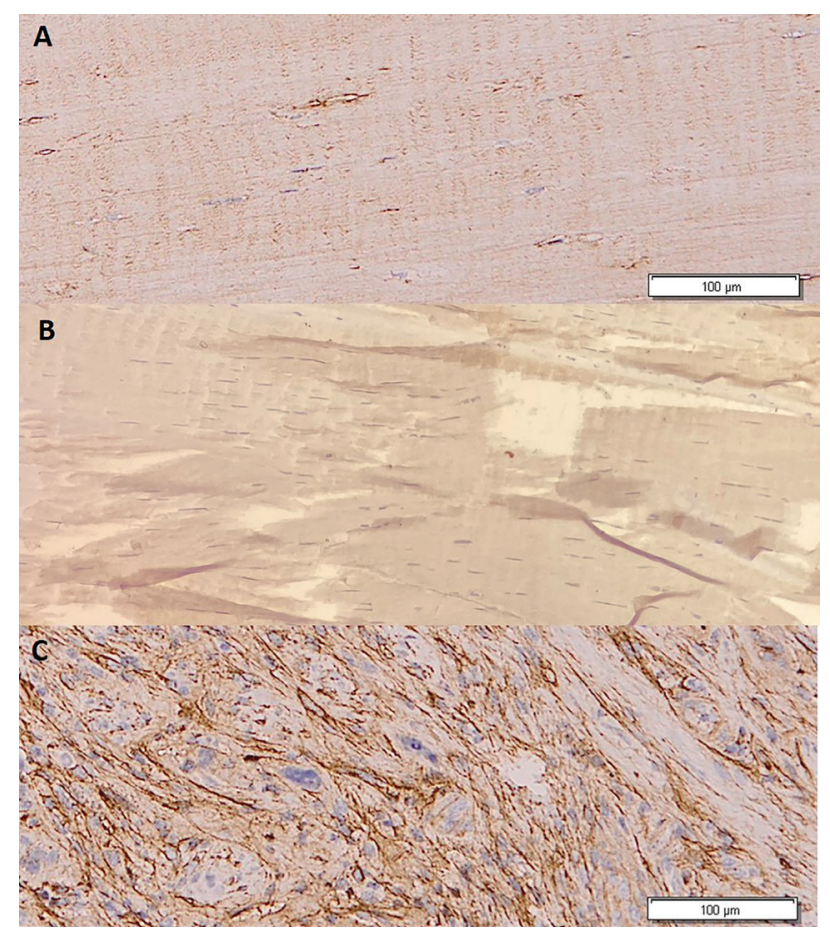

Figure 3. Immunohistochemical expression of fibronectin in Achilles tendon. (A) Focal weak staining; (B) Intense patchy staining; (C) Intense diffuse staining; magnification 100x.
Table II. Linear regression analysis for contracture development.

\begin{tabular}{lrrr}
\hline Variables & Contracture & Non-contracture & p value \\
Age (years) & & & \\
$<60$ & 4 & 11 & 0.036 \\
$\geq 60$ & 11 & 4 & \\
\hline Sex & & & \\
$\quad$ Male & 8 & 9 & 0.215 \\
Female & 7 & 9 & \\
\hline BMI $\left(\mathrm{kg} / \mathrm{m}^{2}\right)$ & & & \\
$<25$ & 3 & 7 & 0.216 \\
$\geq 25$ and $<30$ & 7 & 6 & \\
$\geq 30$ & 5 & 2 & \\
\hline HbA1c $(\%)$ & & & \\
$<6$ & 1 & 3 & 0.356 \\
$\geq 6$ and $<8$ & 7 & 7 & \\
$\geq 8$ & 7 & 5 & \\
\hline TGF- $\beta$ & & & \\
expression & - & - & 0.031 \\
0 & 2 & 8 & \\
1 & 10 & 6 & \\
2 & 3 & 1 & \\
3 & & & \\
\hline
\end{tabular}

and are believed to result from hyperglycemia (19). Decrease of sensation and increased sensory phenomena are also an important major expressions of varieties of diabetic polyneuropathies that contribute to foot ulceration due to loss of protective sensibility to external pressure or trauma (21). Chronic non-healing ulcers are frequently observed at pressure points of the lower extremities (20). Soft tissue plantar to the forefoot is normally subjected to vertical ground reactive and shear forces $(4,22)$. In those cases in which propulsive phase pronation is great, minute haemorrhages develop in the skin at points of the greatest concentration of force. Limited joint mobility may predispose the diabetic foot to ulceration by producing high plantar pressure during gait. Equinus is the primary mechanical common denominator that leads to the majority of acquired non-traumatic foot and ankle problems by indirect leveraged means as well as direct forces along the posterior/plantar chain (23). Combination of high plantar pressures and sensory neuropathy has been well linked to plantar ulceration. The management of limited joint mobility resulting from tendon contracture included non-operative by regular stretching, and operative such as tendon lengthening. Bezerra et al. reported that the exercise protocol shown to be possible to prevent the progression of diabetic tendon stiffness and reduce blood glucose levels in some animal during the experiments (24). 
The pathogenesis of limited joint mobility is complex and multifactorial, including angiopathy and the correlation with AGEs accumulation due to hyperglycemia (25). All the above are the predispositions of diabetic foot ulceration. Notwithstanding, not all the diabetic patients present plantar ulcerations. Certain comorbidities are considered play a role in pathogenesis of diabetic foot ulceration.

This study found no significant association between $\mathrm{HbA1c}$ level and Achilles tendon contracture. The finding was counterintuitive because higher HbA1c level would be expected to exhibit the highest risk of developing complications including tendon contracture. Predominantly, diabetes is still considered as etiological factor of Achilles equinus contracture. However, chronic hyperglycemia and subsequent AGEs accumulation seems not to be the sole source of fibrosis of the affected tendons.

ECM turn-over is characterized by a balance between matrix formation and matrix degradation. AGEs is not the sole cause of ECM turn-over. Factors that regulate ECM formation include multiple forms of growth factors such as TGF- $\beta 1$. TGF- $\beta$ is generally accepted to be the main pro-fibrotic factor in diabetic nephropathy (11). Diabetic environment up-regulated TGF- $\beta 1$ expression and bioactivity in glomerular mesangial and proximal tubule cells $(7,26)$. Certain comorbidities has been known to affect TGF- $\beta$ expression, for example cigarette smoking, in which sustained oxidative stress induces a chronic inflammation and cause further release of active TGF- $\beta 1$ (27).

TGF- $\beta$ is a family of growth factors involved in a number of essential cellular functions and contributes to the pathogenesis of tissue fibrosis in most organs (28). High glucose levels and mechanical stretch, particularly in a cyclic fashion, increases production of TGF- $\beta$ by mesangian cells and vascular smooth muscle cells (29). Similarly, fluid shear stress, as would be induced by mechanical loading, increased production of TGF- $\beta$ by cultured osteoblasts. Extracellular signalling molecules that act to increase TGF- $\beta$ production include angiotensin II and thromboxane, as shown in diabetic nephropathy (11). Stimuli that activate latent TGF- $\beta$ include plasmin, thrombospondin, and reactive oxygen species (28).

The three isoforms of TGF- $\beta$ (TGF- $\beta 1, \beta 2$, and $\beta 3$ ) are secreted as inactive latent precursors that require activation prior to binding to the TGF- $\beta$ receptors (30). TGF- $\beta 1$ and 3 play essential roles in cell proliferation and differentiation, immune response, angiogenesis, and tissue repair. While TGF- $\beta 1$ promotes wound healing, it may promote fibrosis when checked. In contrast, TGF- $\beta 3$ may have an anti-fibrotic role in wound healing.

Identification of TGF- $\beta 1$ as a key factor in the cascade of Achilles tendon contracture development and thor- ough understanding of its regulation will contribute into not only prevention but also treatment the contracture. Neutralizing the actions of TGF- $\beta$ with highly specific monoclonal antibodies or with application of antisense technology can effectively prevent the fibrosis (11). One approach is to reduce TGF- $\beta$ gene expression, either by suppressing the initiation of gene transcription or by altering mRNA stability. TGF- $\beta$ mRNA expression is reduced by anti-sense oligonucleotide, interferon $\alpha$, and anti-oxidants such as $\alpha$-tocopherol (28). Another approach directly targets circulating TGF- $\beta$. Thus, administration of antiTGF- $\beta$ antiserum at the time of induction of experimental mesangial proliferative glomerulonephritis suppresses the accumulation of ECM and histologic manifestation of disease $(28,31)$.

Along with TGF- $\beta 1$ expression, age was found to be a significant determinant of contracture in this study. The common use of the terms "decrease flexibility" or "increased stiffness" in association with the decrease in maximal passive dorsiflexion ROM implies that shortened calf muscle-tendon unit may become stiffer with aging, even in active adults without related pathologies (32). Prior studies has also reported some contributing factors to increased TGF- $\beta 1$ level, such as the duration of cigarette smoking (33).

This study has limitations. We identified our patients based on the surgery indication, thus, other than small sample size we cannot account for patients without wound who had not presented for evaluation. We were unable to adjust our analyses for multiple factors such as vascular status, neuropathic severity, and smoking habits due to relatively small group sizes. The more objective parameters should be done to assess the clinical examination of tendon contracture, for example, using ultrasound techniques as described by Kuo et al. (34). However, this study may provide the framework to define the diabetic foot management algorithm, particularly regarding the role of TGF- $\beta 1$ in Achilles tendon contracture pathogenesis.

The results of this study revealed that TGF- $\beta 1$ play a role in the pathogenesis of Achilles tendon contracture in diabetic foot other than chronic hyperglycemia. The involvement of TGF- $\beta 1$ in contracture or tissue fibrosis suggest that TGF- $\beta 1$-mediated pathways may be one of therapeutic targets for diabetic foot managements. This study research can contribute a more detailed understanding of the role of TGF- $\beta 1$ in pathogenesis of equinus contracture of Achilles tendon in diabetes population, which leads to the development of plantar ulcerations. Further studies to identify the determinants of increasing TGF- $\beta 1$ expression and tissue level, can be performed based on this study. Clinical benefits of this study include yielding information on significance of increasing TGF- $\beta 1$ activity in Achilles tendon contrac- 
tures, thus the clinician can identify and control the causative factors, as well as the therapeutic interventions.

\section{FUNDINGS}

The authors disclosed receipt of the following financial support for the research, authorship, and publication of this article: This work was supported by the Universitas Padjadjaran Internal Research Grant (Grant No. 3855/UN6.C/ LT/2019 and No. 1427/UN6.3.1/LT/2020).

\section{REFERENCES}

1. Geraci A, Bianchi R, Sanfilippo A, D’Arienzo M. Dupuytren contracture in diabetic hand. Endocrinology Stud 2011;1(1):2.

2. Pemayun TGDP, Naibaho R. Clinical profile and outcome of diabetic foot ulcer, a view from tertiary care hospital in Semarang, Indonesia. Diabet Foot Ankle 2017;8(1):1-7.

3. Santoso M, Yuliana M, Mujono W, Kusdiantomo A. Pattern of Diabetic Foot at Koja Regional General Hospital, Jakarta, from 1999 tp 2004. Acta Med Indones 2005;37(4):187-9.

4. Laborde J. Tendon Lengthening for Neuropathic Foot Problem. Orthopedics 2010;33:319-26.

5. Coombes BK, Tucker K, Hug F, et al. Relationships between cardiovascular disease risk factors and Achilles tendon structural and mechanical properties in people with Type 2 Diabetes. Muscles Ligaments Tendons J 2019;9(3):395-404.

6. Smith LL, Burnet SP, McNeil JD. Musculoskeletal manifestations of diabetes mellitus. Br J Sports Med 2003;37(1):30-5.

7. Ban CR, Twigg SM. Fibrosis in diabetes complications: Pathogenic mechanisms and circulating and urinary markers. Vasc Health Risk Manag 2008;4(3):575-96.

8. Goldin A, Beckman JA, Schmidt AM. Advanced glycation end products: sparking the development of diabetic vascular injury. Circulation 2006;114:597-605.

9. Snedeker JG, Gautieri A. The role of collagen crosslinks in ageing and diabetes - the good, the bad, and the ugly. Muscles Ligaments Tendons J 2014;4(3):303-8.

10. Lichtman MK, Otero-Vinas M, Falanga V. Transforming growth factor beta (TGF- $\beta$ ) isoforms in wound healing and fibrosis. Wound Repair Regen 2016;24(2):215-22.

11. Goldfarb S, Ziyadeh FN. TGF-beta: a crucial component of the pathogenesis of diabetic nephropathy. Trans Am Clin Climatol Assoc 2001;112:27-33.

12. Frykberg RG, Bowen J, Hall J, TallisT A, Tierney E, Freeman D. Prevalence of equinus in diabetic versus nondiabetic patients. J Am Podiatr Med Assoc 2012;102(2):84-8.

13. Padulo J, Oliva F, Frizziero A, Maffulli N. Basic principles and recommendations in clinical and field Science Research: 2018 Update. Muscles Ligaments Tendons J 2018;8(3):305-7.

14. Pankov R, Yamada KM. Fibronectin at a glance. J Cell Sci 2002;115:3861-3.

15. Casscells W, Kimura H, Sanchez JA, Yu ZX, Ferrans VJ. Immunohistochemical study of fibronectin in experimental myocardial infarction. Am J Pathol 1990;137(4):801-10.

16. Orem C, Celik S, Orem A, Calapoglu M, Erdol C. Increased plasma fibronectin levels in patients with acute myocardial

\section{ACKNOWLEDGEMENTS}

The authors wish to acknowledge the helpful insight and expertise from Prof. Bethy S. Hernowo, dr, SpPA(K), Ph.D, Department of Anatomical Pathology, Universitas Padjadjaran Medical School/Hasan Sadikin Hospital for the invaluable technical support on this study.

\section{CONFLICT OF INTERESTS}

The authors declare that they have no conflict of interests.

infarction complicated with left ventricular thrombus. Thromb Res 2002;105(1):37-41.

17. Xu Z, Wang S, Wu M, Zeng W, Wang X, Dong Z. TGF beta 1 and HGF protein secretion by esophageal squamous epithelial cells and stromal fibroblasts in oesophageal carcinogenesis. Oncol Lett 2013;6(2):401-6.

18. Yan LJ. Pathogenesis of Chronic Hyperglycemia: From Reductive Stress to Oxidatixe Stress. J Diabetes Res 2014;2014:137919.

19. Dryden M, Baguneid M, Eckmann C, et al. Pathophysiology and burden of infection in patients with diabetes mellitus and peripheral vascular disease: focus on skin and soft tissue infections. Clin Microbiol Infect 2015;21(Suppl2):27-32.

20. Xu L, Kanasaki K, Kitada M, Koya D. Diabetic angiopathy and angiogenic effects. Fibrogenesis Tissue Repair 2012;5:13.

21. Dyck PJ, Herrmann DN, Staff NP, Dyck JB. Assessing Decreased Sensation and increased Sensory Phenomena in Diabetic Polyneuropathies. Diabetes 2013;62(11):3677-86.

22. Brockett CL, Chapman GJ. Biomechanics of the ankle. Orthop Trauma 2016;30(3):232-8.

23. Amis J. The Split Second Effect: The Mechanism of How Equinus Can Damage the Human Foot and Ankle. Front Surg 2016;3(38).

24. Bezerra MA, da Silva Nery C, de Castro Silveira PV, et al. Previous physical exercise slows down the complications from experimental diabetes in the calcaneal tendon. Muscles Ligaments Tendons J 2016;6(1):97-103.

25. Van Gils CC, Roeder B. The effect of ankle equinus upon the diabetic foot. Clin Podiatr Med Surg 2002;19:391-409.

26. Vasiliki-Maria K, Theodora P, Ioanna M, Alexandros T, Areistidhs G, Sioga A. TGF-b and Diabetes Mellitus. J Pharm Pharmacol 2016;4:1-4.

27. Marwick JA, Kirkham P, Gilmour PS, Donaldson K, Macnee W, Rahman I. Cigarette smoke-induced oxidative stress and TGF-beta1 increase p21waf1/cip1 expression in alveolar epithelial cells. Ann N Y Acad Sci 2002;973:278-83.

28. Branton MH, Kopp JB. TGF-beta and fibrosis. Microbes Infect 1999;1(15):1349-65.

29. Riser BL, Cortes P, Yee J, et al. Mechanical strain- and high glucose-induced alterations in mesangial cell collagen metabolism: role of TGF-beta. J Am Soc Nephrol 1998;9(5):827-36.

30. Penn JW, Grobbelaar AO, Rolfe KJ. The role of the TGF- $\beta$ family in wound healing, burns and scarring: a review. Int J Burns Trauma 2012;2(1):18-28. 
31. Border WA, Okuda S, Languino LR, Sporn MB, Ruoslahti E. Suppression of experimental glomerulonephritis by antiserum against transforming growth factor beta 1. Nature 1990;346(6282):371-4.

32. Gajdosik RL, Vander Linden DW, Williams AK. Influence of age on length and passive elastic stiffness characteristics of the calf muscle-tendon unit of women. Phys Ther 1999;79(9):827-38.
33. Mihailichenko D, Pertseva T. Influence of tobacco-smoking on serum level of transforming growth factor (TGF) beta 1 in COPD patients. Eur Resp J 2017;50.

34. Kuo CY, Lee WN, Fong SSM, et al. Ultrasound Tissue Characteristics of Diabetic Muscles and Tendons: Associations with Strength and Laboratory Blood Tests. Muscles Ligaments Tendons J 2020;10(3):399-407. 